\title{
Inhibition of Fungal Appressorium Formation by Pepper (Capsicum annuum) Esterase
}

\author{
Young Soon Kim, ${ }^{1}$ Hyun Hwa Lee, ${ }^{1}$ Moon Kyung Ko, ${ }^{1}$ Chae Eun Song, ${ }^{1}$ Cheol-Yong Bae, ${ }^{2}$ \\ Yong Hwan Lee, ${ }^{2}$ and Boung-Jun Oh ${ }^{1}$ \\ ${ }^{1}$ Kumho Life and Environmental Science Laboratory, Korea Kumho Petrochemical Co. Ltd., 1 Oryong-dong, \\ Puk-gu, Kwangju 500-712, Korea; ${ }^{2}$ School of Applied Biology and Chemistry and RCNBMA, Seoul \\ National University, Suwon 441-744, Korea \\ Accepted 21 September 2000.
}

\begin{abstract}
A pepper esterase gene (PepEST) that is highly expressed during an incompatible interaction between pepper (Capsicum annuum) and the anthracnose fungus Colletotrichum gloeosporioides has been previously cloned. Glutathione-S-transferase-tagged recombinant PepEST protein expressed in Escherichia coli showed substrate specificity for $p$-nitrophenyl esters. Inoculation of compatible unripe pepper fruits with $C$. gloeosporioides spores amended with the recombinant protein did not cause anthracnose symptoms on the fruit. The recombinant protein has no fungicidal activity, but it significantly inhibits appressorium formation of the anthracnose fungus in a dosedependent manner. An esterase from porcine liver also inhibited appressorium formation, and the recombinant protein inhibited appressorium formation in the rice blast fungus, Magnaporthe grisea. Inhibition of appressorium formation in $M$. grisea by the recombinant protein was reversible by treatment with cyclic AMP (cAMP) or 1,16hexadecanediol. The results suggest that the recombinant protein regulates appressorium formation by modulating the cAMP-dependent signaling pathway in this fungus. Taken together, the PepEST esterase activity can inhibit appressorium formation of $C$. gloeosporioides, which may result in protection of the unripe fruit against the fungus.
\end{abstract}

Carboxylesterases are enzymes that catalyze the hydrolysis of compounds containing an ester bond. Genes encoding esterase or lipase enzymes have been studied mainly in mammals and microbes (Contreras et al. 1996; Feller et al. 1991; Kok et al. 1993; Langin et al. 1993; Osterund et al. 1997). Lipases in plants have been studied largely in germinating oil seeds, where they provide energy for embryonic growth (Huang 1987). In plant-microbe interactions, a tobacco esterase gene, $h s r 203 \mathrm{~J}$, has been isolated from tobacco in a hypersensitive reaction against the pathogenic bacterium Ralstonia solanacearum (Badounin et al. 1997; Pontier et al. 1994). Recently, the EDS1 gene that is an essential component of $R$ gene-mediated disease resistance in Arabidopsis spp. has been isolated and found to share homology with eukaryotic lipases

Corresponding author: B. J. Oh; E-mail: bjoh@ksc.kumho.co.kr
(Falk et al. 1999). In addition, Arabidopsis PAD4, a gene required for expression of multiple defense responses after pathogen infection, encodes a lipase that contains a lipase motif and the putative lipase catalytic triad (Jirage et al. 1999). The physiological roles of these enzymes in plant defense mechanisms, however, remain unclear.

Colletotrichum gloeosporioides (Penz.) Penz. \& Sacc. in Penz. is the causal agent of anthracnose diseases affecting fruit crops (Daykin 1984; Oh et al. 1998). The initial infection sequence of $C$. gloeosporioides consists of conidium germination and appressorium formation (Bailey et al. 1992). Afterward, the infection hypha are produced from the appressorium and penetrate the host tissues to colonize the host. In the pepper-C. gloeosporioides pathosystem, only mature unripe fruits showed compatible interaction, whereas ripe fruits were incompatible for interaction (Kim et al. 1999; Oh et al. 1998). A lower level of appressorium formation was observed in the incompatible interaction compared with the compatible interaction. This suggests that appressorium formation is positively linked to the development of anthracnose disease in this pathosystem.

We cloned a pepper esterase gene (PepEST) that is highly expressed during the incompatible interaction between the ripe fruit and $C$. gloeosporioides (Ko and Oh, unpublished results). Here we report that the recombinant PepEST protein expressed in Escherichia coli exhibited substrate specificity in hydrolyzing $p$-nitrophenyl esters. The recombinant PepEST inhibited appressorium formation of the anthracnose fungus in a dose-dependent manner and protected pepper fruits against C. gloeosporioides infection. We also propose that the recombinant PepEST affects a signal transduction pathway(s) involved in appressorium formation on the basis of experimental results obtained with the rice blast fungus, Magnaporthe grisea.

The open reading frame of PepEST cDNA (AF122821) was amplified by polymerase chain reaction and inserted in-frame with the glutathione-S-transferase (GST) coding sequence in expression vector pGEX-6p-1 (Pharmacia Biotech, Uppsala, Sweden) between an EcoRI and XhoI site. The GST-PepEST fusion protein was expressed and purified according to the manufacturer's instructions. Protein content was determined following the Bradford procedure (1979). 
Esterase activity was measured as the rate of hydrolysis of $p$-nitrophenyl esters that were determined spectrophotometrically at $400 \mathrm{~nm}$ in a Beckmann spectrophotometer (Beckmann Instruments, Fullerton, CA, U.S.A.) (Heymann et al. 1981). The esterase activity was measured at $30^{\circ} \mathrm{C}$ in a reaction mixture consisting of $0.2 \mathrm{ml}$ of $0.5 \mathrm{M} \mathrm{N}$-2-hydroxyethylpiperazine- $N^{\prime}$-2-ethanesulfonic acid, $\mathrm{pH} 8.0,1.8 \mathrm{ml}$ of 1 $\mathrm{mM} p$-nitrophenyl esters, and $20 \mu \mathrm{g}$ of the recombinant PepEST. The specific activity in relation to the acyl chain length was measured with $p$-nitrophenyl acetate $\left(\mathrm{C}_{2}\right), p$-nitrophenyl butyrate $\left(\mathrm{C}_{4}\right)$, and $p$-nitrophenyl laurate $\left(\mathrm{C}_{12}\right)$. All measurements were corrected for nonenzymatic hydrolysis of $p$ nitrophenyl esters.

A monoconidial isolate of $C$. gloeosporioides was cultured on potato dextrose agar (Difco, Detriot, MI, U.S.A.) for 5 days in the dark at $28^{\circ} \mathrm{C}$. Conidia were harvested and suspended in sterile distilled water. Ten microliters of spore suspension $\left(5 \times 10^{5}\right.$ spores per milliliter) was used in drop inoculations in vitro and in vivo and amended with $10 \mu \mathrm{l}$ (to a final concentration of $100 \mu \mathrm{g}$ ) of recombinant PepEST, GST, esterase from porcine liver (Sigma, St. Louis, MO, U.S.A.), or sterile water (as the control) per milliliter and applied to cover glasses. The cover glasses were incubated in humidified chambers at $25^{\circ} \mathrm{C}$ in the dark for $24 \mathrm{~h}$. After the spore suspension was stained with $0.1 \%$ (wt/vol) cotton blue in lactophenol, spore germination and appressorium formation on the cover glasses were observed with a microscope (Kim et al. 1999). Dosage-effect experiments for the recombinant protein or the esterase on fungal morphogenesis were performed by the same procedure. Inoculation tests with the use of spores amended with $100 \mu \mathrm{g}$ of the recombinant PepEST or GST per milliliter were performed on healthy unripe and ripe fruits as previously described (Oh et al. 1998). Unripe mature-green and ripe red fruits of pepper cultivar Nokkwang were raised under greenhouse conditions (Oh et al. 1998).

$M$. grisea 70-15 was provided by E. Ellingboe of the University of Wisconsin. Fungal cultures were grown on oatmeal agar (50 g of oatmeal per liter) at $22^{\circ} \mathrm{C}$ under fluorescent light to promote conidiation. Conidia were collected from 10-dayold cultures and washed twice with distilled water. Appressorium formation in $M$. grisea was measured on GelBond film (FMC BioProducts, Rockland, ME, U.S.A.) as previously described (Lee and Dean 1993). A 6- $\mu$ l drop of spore suspension $\left(5 \times 10^{5}\right.$ spores per milliliter) was placed on GelBond film, sealed in a moistened box, and incubated at $24^{\circ} \mathrm{C}$ for 24 $\mathrm{h}$. The percentages of germinated and germ tubes forming appressoria were determined by direct microscopic examination of at least 100 spores per replicate in at least three experiments with three replicates per treatment. Dilutions of the recombinant PepEST (final concentrations, per milliliter, were 10, $5,2.5,1.25,0.625$, and $0.3125 \mu \mathrm{g}$ ) were added to the spore suspension. In the complementation assays, cyclic AMP (cAMP) $(10 \mathrm{mM})$ or 1,16 -hexadecanediol $(0.01 \mathrm{mM})$ was added to spore suspensions in the presence of the recombinant PepEST.

GST-tagged recombinant PepEST was produced in E. coli and purified to near homogeneity. The recombinant protein was capable of hydrolyzing $p$-nitrophenyl esters that were used as substrate for carboxylesterase activity, whereas the GST protein could not degrade these substrates. We used $p$ nitrophenyl esters to examine the enzymatic activities according to acyl chain length. The enzyme activities of the recombinant protein were $192 \mathrm{nmol} / \mathrm{min} / \mathrm{mg}$ for $p$-nitrophenylacetate $\left(\mathrm{C}_{2}\right), 24 \mathrm{nmol} / \mathrm{min} / \mathrm{mg}$ for $p$-butyrate $\left(\mathrm{C}_{4}\right)$, and 0.1 $\mathrm{nmol} / \mathrm{min} / \mathrm{mg}$ for $p$-laurate $\left(\mathrm{C}_{12}\right)$. The activity was maximal for $p$-nitrophenylacetate, decreased 10 -fold for $p$-butyrate, and was much lower for $p$-laurate.

It has been reported that bean inoculation with the phytopathogenic fungus Rhizoctonia solani amended with fungal cutinases or esterases did not cause web blight symptoms (Parker and Köller 1998). We therefore tested whether the PepEST protein had the ability to prevent anthracnose disease symptoms on pepper fruits caused by $C$. gloeosporioides. Spore suspensions were drop inoculated on unripe and ripe pepper fruits. Typical anthracnose symptoms with necrotic sunken lesions were observed on the unripe fruit within 5 days after inoculation, as we previously observed (Oh et al. 1998) (Fig. 1A). However, spores amended with $100 \mu \mathrm{g}$ of the recombinant protein per milliliter were incompatible with the unripe fruits (Fig. 1B). The incompatible ripe fruit used as a positive control showed no anthracnose symptoms (Kim et al. 1999). The treatment of fruits with the recombinant protein alone did not cause any macroscopic changes (data not shown), whereas application of a spore suspension amended with $100 \mu \mathrm{g}$ of GST protein per milliliter did produce disease symptoms on the unripe fruit. Thus, our data suggest that the PepEST protein has a protective activity that prevents anthracnose disease development on unripe fruit infected with $C$. gloeosporioides.

To further elucidate the protective activity of the recombinant PepEST described above, we investigated whether the recombinant protein had a direct effect on fungal growth in vitro. Spores of $C$. gloeosporioides were germinated on cover glasses in the presence of $100 \mu \mathrm{g}$ of recombinant PepEST protein, GST, porcine esterase, or sterile water per milliliter. Neither the recombinant protein, GST, nor the porcine esterase had any fungicidal effect. The spores amended with water germinated at a rate of $63 \%$ (number of germinated spores $\div$ total number of spores observed $\times 100$ ) after $3 \mathrm{~h}$ of incubation and $92 \%$ after $9 \mathrm{~h}$ of incubation (Fig. 2A) (Kim et al. 1999). Afterward, the germination rate increased only slightly and was maintained for up to $24 \mathrm{~h}$ of incubation. Spores amended with the recombinant protein germinated at a rate of $45 \%$ after $3 \mathrm{~h}$ of incubation and $75 \%$ after $24 \mathrm{~h}$ of incubation. GST or the porcine esterase also caused a reduction in the germination rate. The reduction of the germination rate in the presence of GST or the porcine esterase, however, was less than that observed with the recombinant PepEST protein.

We then examined the effect of the recombinant PepEST on appressorium formation. Appressorium formation of $C$. gloeosporioides amended with sterile water was observed after $3 \mathrm{~h}$ of incubation (Fig. 2B). After $24 \mathrm{~h}$, the appressorium formation rate had increased to $82 \%$ (the number of spore with appressorium $\div$ total number of spores observed $\times 100$ ). C. gloeosporioides amended with the recombinant protein didnot form an appressorium before $6 \mathrm{~h}$ of incubation. Maximal appressorium formation by the fungus in the presence of the recombinant protein was $34 \%$ after $24 \mathrm{~h}$ of incubation. In particular, the fungus treated with the recombinant protein exhibited mycelial growth but without appressorium formation (Fig. 2C). The appressorium formation after $24 \mathrm{~h}$ of incubation in the presence of GST or the liver esterase was $62 \%$ 
and $41 \%$, respectively. Taken together, these results indicate that the recombinant PepEST more significantly affects appressorium formation than spore germination.

We then examined the dose dependency of the inhibition of spore germination and appressorium formation by the recombinant PepEST. The fungal spores were amended with 1, 10, 100 , and $1,000 \mu \mathrm{g}$ of recombinant PepEST protein or porcine
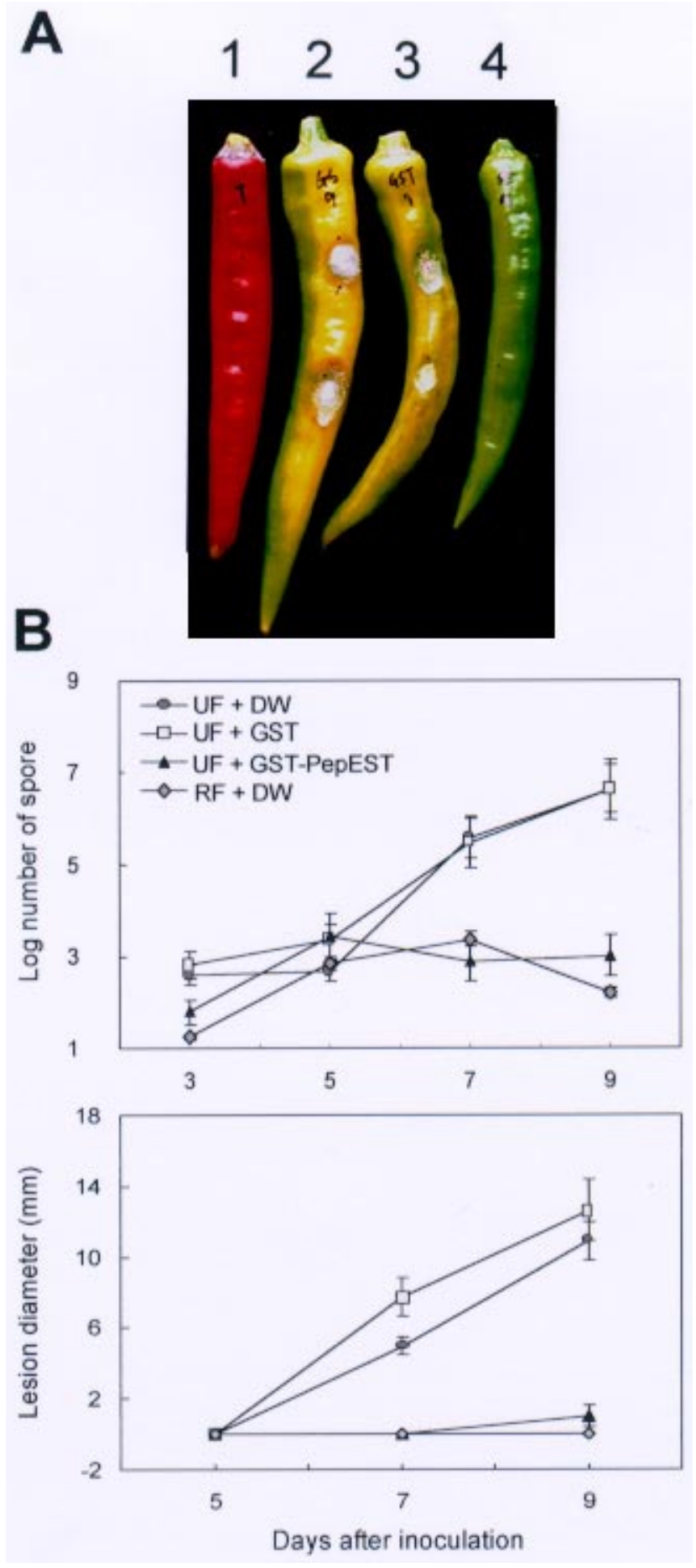

esterase per milliliter. One-hundred micrograms of the recombinant protein per milliliter inhibited spore germination only slightly, whereas $1,000 \mu \mathrm{g}$ of the recombinant protein per milliliter did not produce an inhibition, indicating that the recombinant protein had no significant effect on spore germination (Fig. 3A). However, the porcine esterase did inhibit spore germination in the dose-dependent manner, and the recombinant protein and porcine esterase significantly inhibited appressorium formation in a dose-dependent manner (Fig. 3B).

We also compared the hydrolyzing activity of the recombinant PepEST with that of the porcine esterase with $p$-nitrophenylbutyrate in vitro (Fig. 3C). The hydrolyzing activity of the esterase (10 ng) was much higher than that of the recombinant protein $(1 \mu \mathrm{g})$. A boiled GST-PepEST fusion protein did not affect the inhibition of spore germination and appressorium formation and did not hydrolyze $p$-nitrophenylbutyrate.

We next studied the effect of recombinant PepEST on appressorium formation of $M$. grisea. Spore suspensions of $M$. grisea amended with a series of dilutions of the recombinant protein were incubated on the hydrophobic surface of GelBond film for $24 \mathrm{~h}$. Ten micrograms of recombinant protein per milliliter significantly inhibited appressorium formation (Table 1). Greater dilutions of the recombinant protein gradually lost their inhibitory capacity in a dose-dependent manner. Concentrations of 0.625 and $0.3125 \mu \mathrm{g}$ of recombinant protein per milliliter did not have any significant inhibitory effect on the appressorium formation in $M$. grisea.

Table 1. Effect of the recombinant pepper esterase gene (PepEST) on appressorium formation in Magnaporthe grisea

\begin{tabular}{lc}
\hline Treatment & $\begin{array}{c}\text { Appressorium formation } \\
(\% \pm \text { standard error })\end{array}$ \\
\hline Water control & $76.2 \pm 9.1$ \\
Buffer control & $79.8 \pm 10.4$ \\
PepEST (10) & a \\
PepEST (5) & $38.4 \pm 5.9$ \\
PepEST (2.5) & $46.1 \pm 3.2$ \\
PepEST $(1.25)$ & $44.7 \pm 3.3$ \\
PepEST $(0.625)$ & $54.3 \pm 3.1$ \\
PepEST $(0.3125)$ & $68.6 \pm 6.8$ \\
PepEST (10) + 10 mM cyclic AMP & $70.7 \pm 11.1$ \\
PepEST $(10)+0.01 \mathrm{mM} 1,16-$ & $70.4 \pm 12.4$ \\
hexadecanediol & $93.7 \pm 1.6$ \\
\hline
\end{tabular}

${ }^{a}$ Microgram concentration of recombinant PepEST per ml.

\section{$\leftarrow$}

Fig. 1. Protection of the unripe fruit of pepper against Colletotrichum gloeosporioides infection by the recombinant pepper esterase (PepEST). A, Anthracnose symptoms on the pepper fruits observed 9 days after inoculation. (1) The incompatible ripe fruit inoculated with the fungus produced no disease symptoms. (2) Compatible unripe fruit treated with the fungus and amended with $10 \mu \mathrm{l}$ of sterile water or (3) $100 \mu \mathrm{g}$ of glutathione-S-transferase (GST) protein per ml showed typical anthracnose symptoms. (4) No apparent symptoms developed on unripe fruit treated with the fungus that was amended with $100 \mu \mathrm{g}$ of GST-PepEST protein per $\mathrm{ml}$. B, Anthracnose lesion diameter and number of spores were measured on the unripe (UF) and ripe fruit (RF) infected with the fungus and amended with $10 \mu \mathrm{l}$ of sterile water (DW), $100 \mu \mathrm{g}$ of GST per ml, and $100 \mu \mathrm{g}$ of GST-PepEST per ml. RF inoculated with the fungus was used as the control for incompatible interaction. Lesion diameter and number of spores were measured 3, 5, 7, and 9 days after inoculation. Each value for lesion diameter and number of spores represents the mean \pm standard error of 60 and 15 replicates, respectively. 
As a first step to dissect the inhibition mechanism(s), we looked for an effect of the recombinant PepEST protein on signal-transduction pathways involved in appressorium formation. The inhibition of appressorium formation on the hydrophobic surface of GelBond by the recombinant protein was reversible by treating the spores with cAMP or 1,16hexadecanediol. The appressoria induced by cAMP or 1,16hexadecanediol in the presence of recombinant PepEST protein were well melanized and indistinguishable from those formed in the untreated control. We also found that 1,16hexadecanediol was much more effective than cAMP in inducing appressorium formation.

Genes (EDS1, hsr203J, and PAD4) encoding a lipase motif (GXSXG) and the putative catalytic triad in lipases composed of serine (Ser), aspartic acid (Asp), and histidine (His) have been isolated from various plant tissues involved in plantmicrobe interactions (Falk et al. 1999; Jirage et al. 1999; Pontier et al. 1994). We cloned a PepEST that was highly expressed during an incompatible interaction between pepper fruit and C. gloeosporioides. Recombinant PepEST protein expressed in E. coli exhibited substrate specificity for $p$ - nitrophenyl esters in vitro. The recombinant PepEST activity was maximal for $p$-nitrophenylacetate, decreased significantly for $p$-butyrate, and was barely detectable for $p$-laurate. These data indicate that the recombinant protein was active as a single polypeptide and most effective on short-chain acyl esters. The substrate specificity of the PepEST thus differed from that of HSR203J, a tobacco esterase that was as active on $p$ nitrophenylacetate and $p$-butyrate (Baudouin et al. 1997). Although both esterases exhibited somewhat different substrate specificities, they may have similar natural substrates. This possibility is suggested by the fact that both esterases accumulate highly only during incompatible interactions. The exact physiological role for the esterases in plant defenses, however, has not yet been determined.

Appressorium formation by many fungal pathogens is a prerequisite for the infection of a host plant (Staple and Hoch 1987). In a previous study (Kim et al. 1999), a lower level of appressorium formation had been observed on an incompatible ripe fruit compared with a compatible unripe pepper fruit. In this study, we found that the recombinant PepEST could inhibit appressorium formation of C. gloeosporioides,

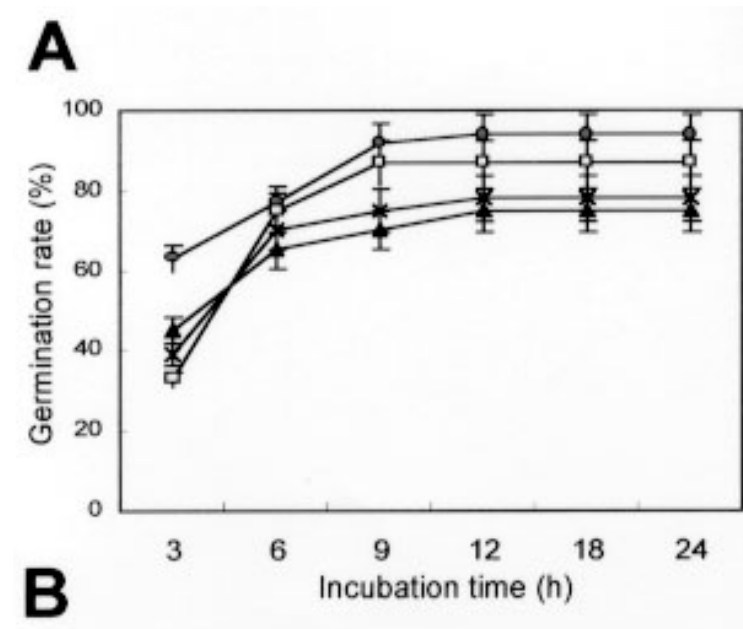

\section{C}
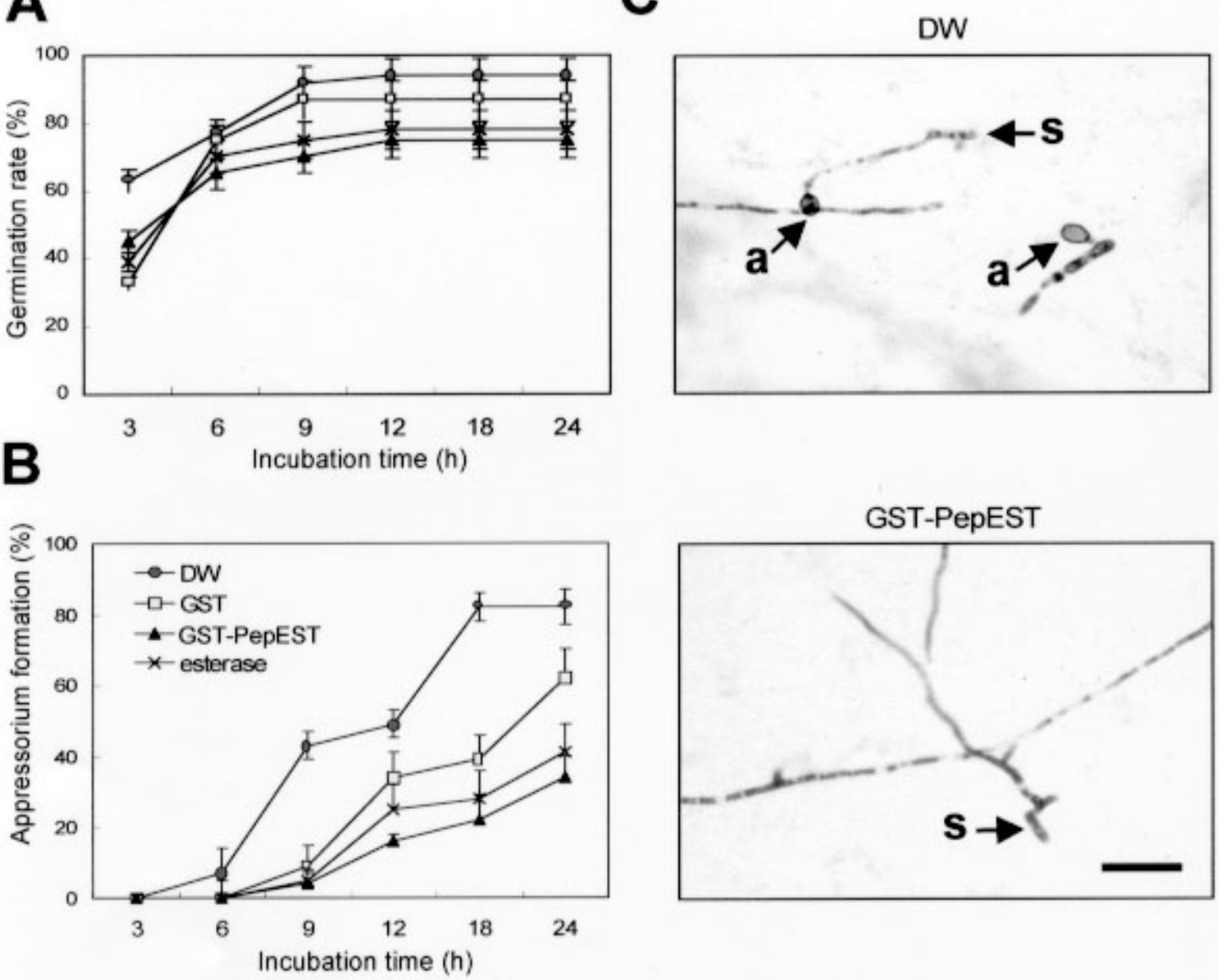

Fig. 2. Effect of the recombinant pepper esterase (PepEST) on spore germination and appressorium formation in Colletotrichum gloeosporioides. Spores amended with $10 \mu \mathrm{l}$ of sterile water (DW), $100 \mu \mathrm{g}$ of glutathione-S-transferase (GST) per ml, $100 \mu \mathrm{g}$ of GST-PepEST per ml, or $100 \mu \mathrm{g}$ of esterase per ml were observed to evaluate $\mathbf{A}$, spore germination and $\mathbf{B}$, appressorium formation on cover glasses. At least 100 spores were counted per replicate. Each value represents the mean \pm standard error of nine replicates. C, Inhibition of appressorium formation in C. gloeosporioides amended with $10 \mu \mathrm{l}$ of the recombinant protein $(100 \mu \mathrm{g} / \mathrm{ml})$ on cover glasses. A spore suspension with DW was used as the control. The fungus treated with the recombinant protein exhibited mycelial growth without appressorium formation (GST-PepEST). The fungus was stained with $0.1 \%$ (wt/vol) cotton blue in lactophenol $24 \mathrm{~h}$ after inoculation. $\mathrm{Bar}=25 \mu \mathrm{m}$. $\mathrm{a}=$ appressorium; $\mathrm{s}=$ spore 
A

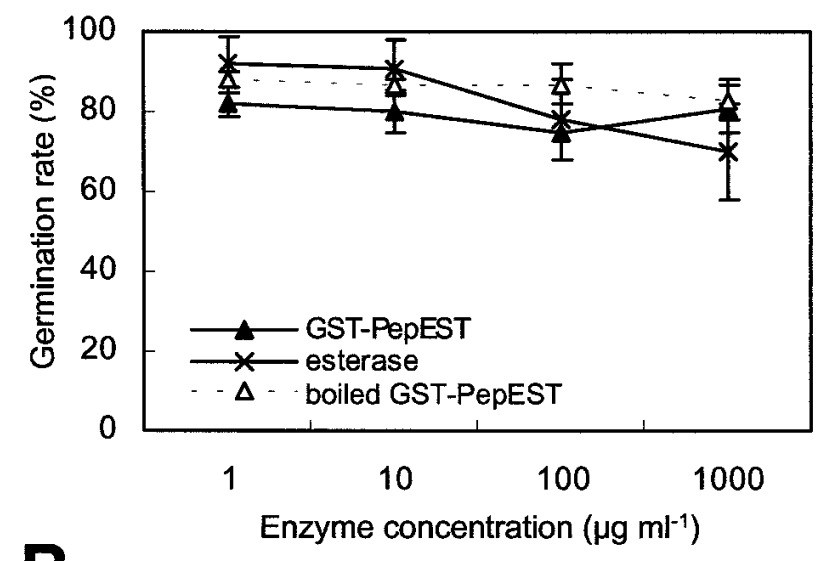

B

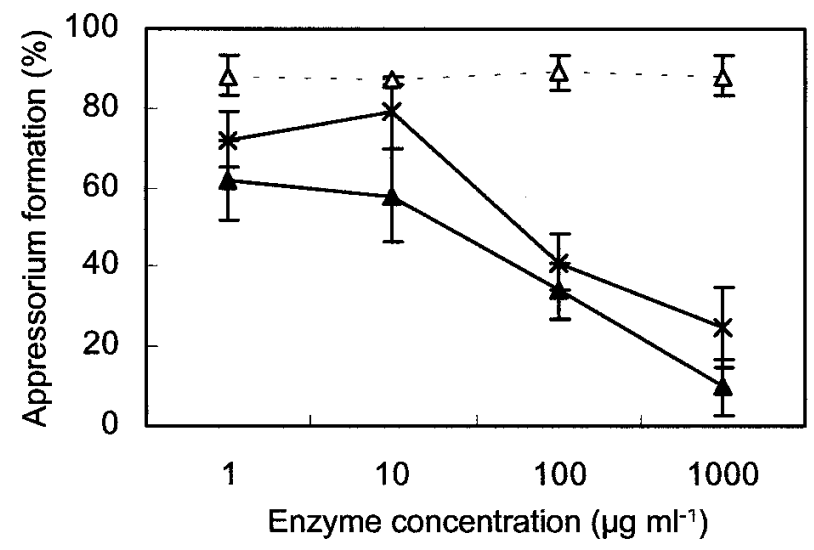

C

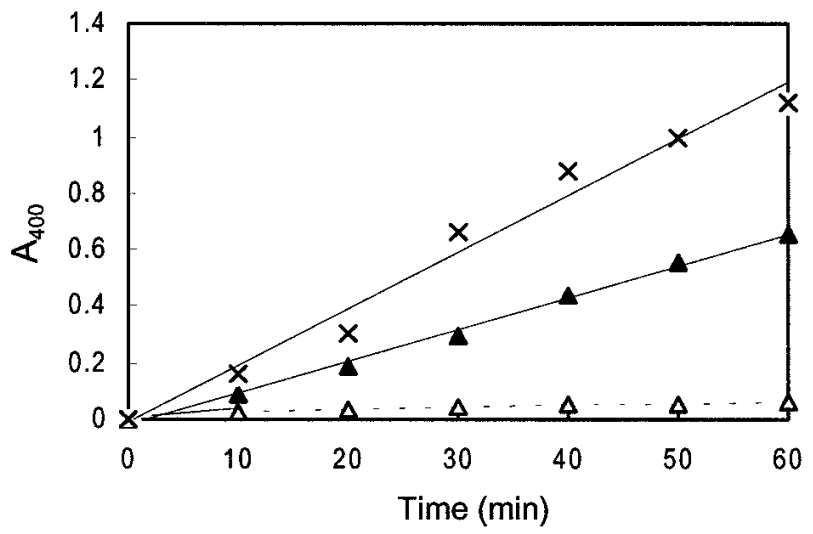

Fig. 3. Effect of recombinant pepper esterase (PepEST) concentration on $\mathbf{A}$, spore germination and $\mathbf{B}$, appressorium formation of Colletotrichum gloeosporioides in vitro. A boiled glutathione-S-transferase (GST)PepEST was used as the negative control. Spore suspensions were amended with $10 \mu \mathrm{l}$ of the recombinant protein, the boiled recombinant protein, or esterase to final concentrations, per milliliter, of 1, 10, 100, and $1,000 \mu \mathrm{g}$. At least 100 spores were counted per replicate. Each value represents the mean \pm standard error of nine replicates. C, Comparison of hydrolyzing activity of the recombinant PepEST $(1 \mu \mathrm{g})$, the boiled recombinant PepEST $(1 \mu \mathrm{g})$, and the esterase $(10 \mathrm{ng})$ on $p$ nitrophenylbutyrate. resulting in the protection of the fruit from infection by the fungus. Higher concentrations of the recombinant PepEST protein and porcine esterase caused a significant reduction in appressorium formation. The boiled recombinant PepEST did not hy drolyze $p$-nitrophenylbutyrate, however, and did not affect the inhibition of appressorium formation. The porcine esterase also protected the unripe fruit against fungal infection (data not shown), suggesting that the inhibition of appressorium formation was caused by the esterase activity of the recombinant PepEST.

The hydrolytic activity of the porcine esterase (10 ng) was similar to that of the recombinant PepEST (1 $\mu \mathrm{g})$ (Fig. 3C). Higher concentrations $(100 \mu \mathrm{g})$ of the esterase per milliliter, however, resulted in less inhibition of appressorium formation tion than the $100 \mu \mathrm{g}$ of the recombinant protein per milliliter (Fig. 3B). This suggests that although the recombinant protein exhibited lower hydrolyzing activity on $p$-nitrophenylbutyrate, the PepEST protein seems to have a specific activity that can strongly inhibit appressorium formation of the fungus.

Many phytopathogenic fungi secrete cutinases that act as esterases, breaking the ester linkages between the cutin molecules of plant cuticles in order to invade plants (Kolattukudy 1985; Köller et al. 1982). Fungal cutinases have a lipase motif (GXSXG) and a catalytic triad composed of Ser, Asp, and His (Sweigard et al. 1992). Interestingly, esterases are used on both sides of the plant-microbe interaction. It has been hypothesized that another role for cutinases may be the induction of disease resistance in plants via the generation of cutin monomers from plant cuticles (Schweizer et al. 1996a; Schweizer et al. 1996b). Exogenous application of the PepEST to the unripe fruit induced the generation of $\mathrm{H}_{2} \mathrm{O}_{2}$ and the expression of defense-related genes (Ko and Oh, unpublished results). These results suggest that PepEST may have the ability to affect fungal morphogenesis as well as induce defense responses similar to those of fungal cutinases.

The inhibition of appressorium formation in M. grisea suggests that PepEST also may have an inhibitory potential against fungi other than the anthracnose fungus. Furthermore, treatment with cAMP or 1,16-hexadecanediol restored the appressorium formation in M. grisea inhibited by PepEST. This suggests that the inhibitory mechanism exhibited by PepEST may operate upstream of the sites of action of cAMP or 1,16-hexadecanediol. A similar phenomenon has been observed previously for these effector chemicals and polyamines (Choi et al. 1998). It is likely that PepEST may decrease intracellular cAMP levels or directly or indirectly increase the requirement for cAMP. Although the precise mechanisms involved in the inhibition of the appressorium formation by PepEST are not yet clear, our data suggest that PepEST exerts its effect by modulating the cAMP and 1,16-hexadecanediol signal transduction pathway.

\section{LITERATURE CITED}

Bailey, J. A., O'Connell, R. J., Pring, R. J., and Nash, C. 1992. Infection strategies of Colletotrichum species. Pages 88-120 in: Colletotrichum: Biology, Pathology and Control. J. A. Bailey and J. A. Jeger, eds. CAB International, Wallingford, U.K.

Baudouin, E., Charpenteau, M., Roby, D., Marco, Y., Ranjeva, R., and Ranty, B. 1997. Functional expression of a tobacco gene related to the serine hydrolase family. Esterase activity towards short-chain dinitrophenyl acylesters. Eur. J. Biochem. 248:700-706. 
Bradford, M. M. 1976. A rapid and sensitive method for the quantitation of microgram quantities of protein utilizing the principle of proteindye binding. Anal. Biochem. 72:248-254.

Choi, W.-B., Kang, S.-H., Lee, Y.-W., and Lee, Y.-H. 1998. Cyclic AMP restores appressorium formation inhibited by polyamines in Magnaporthe grisea. Phytopathology 88:58-62.

Contreras, J. A., Karlsson, M., Osterlund, T., Laurell, H., Svensson, A. and Holm, C. 1996. Hormone-sensitive lipase is structurally related to acetylcholinesterase, bile salt-stimulated lipase, and several fungal lipases. J. Biol. Chem. 271:31426-31430.

Daykin, M. E. 1984. Infection of blueberry fruit by Colletotrichum gloeosporioides. Plant Dis. 68:948-950.

Falk, A., Feys, B. J., Frost, L. F., Jones, J. D. G., Daniels, M. J., and Parker, J. E. 1999. EDS1, an essential component of $R$ gene-mediated disease resistance in Arabidopsis has homology to eukaryotic lipases. Proc. Natl. Acad. Sci. USA 96:3292-3297.

Feller, G., Thirty, M., and Gerday, C. 1991. Nucleotide sequence of the lipase gene lip2 from the Antarctic psychrotroph Moraxella TA144 and site-specific mutagenesis of the conserved serine and histidine residues. DNA Cell Biol. 10:381-388.

Heymann, E., Mentlein, R., and Rix, H. 1981. Hydrolysis of aromatic amide as assay for carboxylesterases-amides. Methods Enzymol. 77:333-344.

Huang, A. H. C. 1987. Lipases. Pages 91-119 in: The Biochemistry of Plants, vol. 9. P. K. Stumpf and E. E. Conn, eds. Academic Press, New York.

Jirage, D., Tootle, T. L., Reuber, T. L., Frost, L. N., Feyes, B. J., Parker, J. E., Ausubel, F. M., and Glazebrook, J. 1999. Arabidopsis thaliana $P A D 4$ encodes a lipase-like gene that is important for salicylic acid signaling. Proc. Natl. Acad. Sci. USA 96:13583-13588.

Kim, K. D., Oh, B. J., and Yang, J. 1999. Differential interactions of a Colletotrichum gloeosporioides isolate with green and red pepper fruits. Phytoparasitica 27:97-106.

Kok, R. G., Christoffels, V. M., Volsman, B., and Hellingwerf, K. J. 1993. Growth-phase-dependent expression of the lipolytic system of Acinetobacter calcoaceticus BD413: Cloning of a gene coding one of the esterases. J. Gen. Microbiol. 139:2329-2342.
Kolattukudy, P. E. 1985. Enzymatic penetration of the plant cuticle by fungal pathogens. Annu. Rev. Phytopathol. 23:223-250.

Köller, W., Allan, C. R., and Kolattukudy, P. E. 1982. Role of cutinase and cell wall degrading enzymes in infections of Pisum sativum by Fusarium soloni f. sp. pisi. Physiol. Plant Pathol. 20:47-60.

Langin, D., Laurell, H., Stenson-Holst, L., Belfrage, P., and Holm, C. 1993. Gene organization and primary structure of human hormonesensitive lipase: Possible significance of a sequence homology with a lipase of Moraxella TA144, an Antarctic bacterium. Proc. Natl. Acad. Sci. USA 90:4897-4901.

Lee, Y. H., and Dean, R. A. 1993. cAMP regulates infection structure formation in the plant pathogenic fungus Magnaporthe grisea. Plant Cell 5:693-700.

Oh, B. J., Kim, K. D., and Kim, Y. S. 1998. A microscopic characterization of the infection of green and red pepper fruits by an isolate of Colletotrichum gloeosporioides. J. Phytopathol. 146:301-303.

Osterlund, T., Contreras, J. A., and Holms, C. 1997. Identification of essential aspartic acid and histidine residues of hormone-sensitive lipase: Apparent residues of the catalytic triad. FEBS Lett. 403:259262.

Parker, D. M., and Köller, W. 1998. Cutinase and other lipolytic esterases protect bean leaves from infection by Rhizoctonia solani. Mol. Plant-Microbe Interact. 11:514-522.

Pontier, D., Godlard, L., Marco, Y., and Roby, D. 1994. hsr203J, a tobacco gene whose activation is rapid, highly localized and specific for incompatible plant/pathogen interactions. Plant J. 5:507-521.

Schweizer, P., Felix, G., Buchala, A., Müller, C., and Métraux, J.-P. 1996a. Perception of free cutin monomers by plant cells. Plant J. 10:331-341.

Schweizer, P., Jeanguenat, A., Whitacre, D., and Métraux, J.-P. 1996b. Induction of resistance in barley against Erysiphe graminis f. sp. hordei by free cutin monomers. Physiol. Mol. Plant Pathol. 49:103-120.

Staple, R. C., and Hoch, C. H. 1987. Infection structures: Form and function. Exp. Mycol. 11:163-169.

Sweigard, J. A., Chumley, F. G., and Valent, B. 1992. Cloning and analysis of CUT1, a cutinase gene from Magnaporthe grisea. Mol. Gen. Genet. 232:174-182. 